\title{
Public Perceptions of Benefits from and Worries over Plant-Made Industrial Products and Plant-Made Pharmaceuticals: The Influence of Institutional Trust
}

\author{
Patrick A. Stewart \\ Department of Political Science, University of Arkansas \\ William P. McLean \\ Department of Political Science, Arkansas State University
}

\begin{abstract}
Although agricultural biotechnology has been a seminal reference point in risk perception studies, public awareness of their exposure to risk deriving from this new technology has been minimal at best. However, recent events indicate there may be growing public concern as new variations of this technology appear. Understanding what drives perceptions of benefits from the third generation of the agricultural biotechnology and what determines public worries are keys for the future of this technology. To this end, this study analyzes survey data from the midsouth region of the United States to construct four separate regression models of perceived benefits from and worries over plant-made industrial products and plant-made pharmaceuticals. Findings suggest that while prior experience with and knowledge about agricultural biotechnology has an impact on perceptions of benefits and worries, trust in farmers plays a highly important role in determining perceptions.
\end{abstract}

KEY WORDS: agricultural biotechnology, plant-made pharmaceuticals, plant-made industrial products, risk perceptions, trust

B iotechnology, specifically agricultural biotechnology, has been a seminal reference point in risk perception studies (Fischhoff \& Fischhoff, 2001; Harrison \& Han, 2005; Midden et al., 2002; Poortinga \& Pidgeon, 2006; Savadori et al., 2004; Siegrist, 2000; Siegrist \& Cvetkovich, 2000; Slovic, 1992; Townsend \& Campbell, 2004; Townsend, Clark, \& Travis, 2004; Wilson et al., 2004). However, in the United States, public perception of risks from this new technology has been minimal at best (Hallman et al., 2004; PEW, 2004; Stewart \& McLean, 2005b). Whether this is a result of these products being relatively unknown to the U.S. public, as genetic innovations in the farmers' fields focus on production characteristics such as herbicide tolerance or insect resistance or of other reasons, such as trust in institutions involved with the production and regulation of food, until recently this issue has had little public salience. However, recent events suggest the potential for increased public concern over the new agricultural biotechnology, especially as new, more visible products appear in farmers' fields and ultimately the marketplace.

A number of factors contributed to the rise in agricultural biotechnology's public profile through national media coverage. Foremost were events in which: genetically modified (GM) animal feed (Starlink corn) entered into the human food supply; the appearance of a scientific article extrapolating from laboratory findings suggested the long-term deleterious effects of corn genetically modified to express bacillus thuriengiensis (Bt), a pesticide, on Monarch butterflies; ${ }^{1}$ and corn plants genetically modified to produce pig vaccine nearly entered the food supply on two occasions (Stewart \& Knight, 2005; Taylor, Tick, \& Sherman, 2004), which raised

(C) 2008 by The Policy Studies Organization. All rights reserved. 
agricultural biotechnology's public profile through national media coverage. More recently, for the past four years an experimental corn plant genetically modified to express the $\mathrm{Bt}$ pesticide and an antibiotic used for marker purposes has been entering the food supply without regulatory approval or the awareness of the company producing it, the farmers growing it, and consumers eating it (Rosenwald, 2005), although U.S. regulators later approved it for public consumption (USDA, 2007). While this corn does not necessarily present a health risk, it underscores problems with the implementation of regulations intended to protect the American public from crops not intended for their consumption entering into the food chain (Stewart, in press).

With the appearance of third-generation products-plants genetically modified to produce industrial products and pharmaceutical drugs-an increased concern by interested publics has become more apparent. This is likely the result of current federal regulations that appear to be falling short of the goal of protecting the U.S. food supply (USDA-OIG, 2005). This concern is apparent in comments received in response to proposed U.S. Department of Agriculture regulatory changes on how plant-made industrial products (PMIPs) and plant-made pharmaceuticals (PMPs) are field-tested. Although many of the comments originated from interest group efforts, especially those by antigenetic engineering and organic food groups, the potential for mainstream public involvement is reflected in comments received from food production organizations wishing to maintain public trust in the food they supply. These comments indicate mainstream food industry concerns over PMIPs and PMPs making their way into the human food supply and not just affecting profits by decreasing sales of affected food products and increasing liability but diminishing public trust in the food production system as a whole (Stewart \& McLean, 2005a).

In spite of concerns raised by the potential for PMIPs and PMPs to enter the food supply, the benefits offered by them may sway public opinion, especially if management strategies ensuring that the food system's integrity is protected are implemented. ${ }^{2}$ Although attitudes and opinions toward first, second, and third generations are strongly related, they are not coterminous (Stewart \& McLean, 2005b). Specifically, in light of public support for new medical biotechnologies (Fischhoff \& Fischhoff, 2001), there might be less concern over PMPs on the basis of their promising medical benefits with direct implications for the individual, as compared with PMIPs, which may not be seen as providing direct individual benefits.

Therefore, in this study we consider determinants of the general public's perceptions of worries about and benefits deriving from the third generation of agricultural biotechnology. We look specifically at PMIPs and PMPs by considering what determines how worried an individual would be if they ate foods with PMIPs or PMPs in them without their knowledge and how much perceived benefit these products would confer to the individual. This is done in light of risk perception studies and recent research concerning the role of emotions in decision making. We then construct causal models determining response to these different technologies based on: perception of potential exposure to each of these types of genetically modified plants, awareness of genetically modified foods in grocery stores and willingness to consume these products, scientific knowledge in terms of objective 
general science knowledge and education levels, trust in federal government agencies and farmers, and finally, background information such as age, sex, and ethnicity. We conclude by discussing the implications of our findings on the potential for PMIPs and PMPs.

\section{Perceptions of Benefits from and Worry Concerning Third-Generation Products}

Much of the psychometric literature on risk perceptions focuses on two descriptive dimensions of how known or unknown a new (or old) technology is and how dreaded that technology is. This approach has been used to characterize risk perceptions of agricultural biotechnology in numerous studies (i.e., Fischhoff \& Fischhoff, 2001; Midden et al., 2002; Savadori et al., 2004; Slovic, 1992; Townsend \& Campbell, 2004; Townsend et al., 2004). However, recent advances in the neurosciences and their application to social science problems have led to researchers better appreciating the role of emotion in the process of decision making (Peters, Burraston, \& Mertz, 2004). The psychometric dimension of dread may be interpreted as reflecting the core emotion of fear/worry, which has a distinct physiological signature-facial expressions, body language and vocalizations, and behavioral implications-by driving decision making (Ekman \& Davidson, 1994; Lewis \& Haviland-Jones, 2004; Panksepp, 1998). This basic emotion of fear/worry has been useful in explaining individual reactions and actions. Fear leads to individuals collecting more information on the focus of their concern (Brader, 2006; Lerner et al., 2003; Marcus, Neuman, \& MacKuen, 2000; Wilson et al., 2004) and relying on their political leaders and institutions to a much greater extent than normal (Lerner et al., 2003; Marcus et al., 2000; Schubert, Stewart, \& Curran, 2002).

Fear may be seen as the dominant emotion driving public concerns over the new agricultural biotechnology. This is likely because of many of its products being intended for personal consumption (i.e., eating) and thus becoming both a public and personal threat. Extant research has documented the role of emotions such as fear/worry on reception of agricultural biotechnology (Stewart \& McLean, 2005a, 2005b; Stewart \& Sorensen, 2000) with fear/worry being an overwhelmingly important factor in the rejection of this technology both in terms of worry over potential environmental harms and possible personal risk. However, and to our knowledge, the emotion of fear/worry as it pertains to agricultural biotechnology has not been systematically studied. Instead, when studied it has tended to be characterized as perceptions of risk (e.g., Midden et al., 2002), the immediate prelude to the emotion of fear.

While benefits from new technologies have often been considered in opposition to fears in a single unified dimension, with risks subtracted from benefits, especially in cost-benefit analyses, benefits may be seen as a subset of how known or unknown a risk is (Slovic, 1992). If a technology, such as agricultural biotechnology, has either a direct benefit or a societal benefit, it is more likely to be seen as more acceptable. In this case, risks and resultant fears may be accepted (or ignored) for the sake of the benefits if the trade-off is seen as advantageous enough. In their study of European public perceptions, Midden and others (2002) found that two factors 
Table 1. Attitudes toward Plant-Made Industrial Products (PMIPs) and Plant-Made Pharmaceuticals (PMPs)

\begin{tabular}{lll}
\hline Variable & \multicolumn{1}{c}{ PMIPs } & \multicolumn{1}{c}{ PMPs } \\
\hline Benefit from (PMIPs/PMPs) & A great deal $=30.3$ & A great deal $=41.3$ \\
& Some $=42.5$ & Some $=33.6$ \\
& A little $=12.2$ & A little $=11.8$ \\
None at all $=13.3$ & Very $=24.9$ \\
Worried about (PMIPs/PMPs) & None at all $=15$ & Quite a bit $=14.1$ \\
& Very $=28.2$ & Moderately $=17.2$ \\
& Quite a bit $=17.7$ & Slightly $=21.0$ \\
Noderately $=19.8$ & Not at all $=22.8$ \\
Very likely $=23.9$ \\
enter the food supply? & Slightly $=18.2$ & Somewhat likely $=43.3$ \\
& Not at all $=16.1$ & Neither likely nor unlikely $=4.6$ \\
& Very likely $=28.3$ & Somewhat unlikely $=13.3$ \\
& Somewhat likely $=37.9$ & Very unlikely $=14.8$
\end{tabular}

emerged, the aforementioned perception of risk and a factor composed of judgments concerning its use, moral acceptability, and encouragement. While our study is not as comprehensive, with only one measure of perceived benefit, it reflects the two-dimensional approach that is well supported both by theory and empirical results.

To assess survey participants' perceptions of worries over and benefits from the third-generation products we first introduced each technological application (PMIPs and PMPs) by giving a short description before asking respondents to assess the technology. PMIPs were described as such: "These are plants that are modified to produce compounds used in manufacturing products such as paper, plastics and laundry products." PMPs were described as "plants genetically modified to produce pharmaceutical drugs. These are plants that are modified to produce compounds used in manufacturing vaccines for diarrhea, antibodies to fight cancer, and drugs to treat such illnesses as cystic fibrosis."

Benefits are assessed by asking "How much benefit do you believe you would personally get from this plant?" and were measured on a four-point scale, while worry is assessed by asking "How worried would you be if you ate food coming from this type of plant?" and was measured on a five-point scale (see Table 1). In both cases, individual benefits and worry are assessed, not potential public and/or environmental benefits and threat. This is done in order to maintain immediate personal salience.

\section{Determinants of Benefits and Risks from PMPs and PMIPs}

Those factors driving perceptions of benefits from the new agricultural biotechnology, namely PMPs and PMIPs, and worry over consuming these plants may be seen as ranging from proximate perceptions to demographic characteristics. Important variables determining risk perceptions have included familiarity with similar technologies, knowledge of science, level of education, trust in producers of the technology and those regulating it, and background information such as age, sex, and ethnicity. Each of these will be discussed at length further in the text.

The key in determining individual assessments of the benefits from the third generation of agricultural biotechnology and what causes individuals to worry is 
Table 2. Determinants of Attitudes toward Plant-Made Industrial Products (PMIPs) and Plant-Made Pharmaceuticals (PMPs)

\begin{tabular}{|c|c|}
\hline $\begin{array}{l}\text { Seen/read/heard much about GM food } \\
\text { in grocery stores? (PEW percentages } \\
\text { in brackets) }\end{array}$ & $\begin{array}{l}\text { A great deal }=8.1(10 \%) \\
\text { Some }=31.7(26 \%) \\
\text { Not too much }=30.3(23 \%) \\
\text { Nothing at all recently }=29.9(39 \%)\end{array}$ \\
\hline $\begin{array}{l}\text { Would you eat GM food? (PEW } \\
\text { percentages in brackets) }\end{array}$ & $\begin{array}{l}\text { Very likely }=9.4(11 \%) \\
\text { Somewhat likely }=30.4(32 \%) \\
\text { Not too likely }=28.8(22 \%) \\
\text { Not at all likely }=31.5(28 \%)\end{array}$ \\
\hline Science knowledge & $\begin{array}{l}0 \text { questions correct }=1.3 \\
1 \text { question correct }=10.1 \\
2 \text { questions correct }=24.4 \\
3 \text { questions correct }=31.5 \\
\text { All questions correct }=32.7\end{array}$ \\
\hline Education & $\begin{array}{l}\text { Less than high school }=8.8 \\
\text { High school }=28.3 \\
\text { Some college/tech }=27.7 \\
\text { Tech grad }=5.1 \\
\text { Bachelors }=20.1 \\
\text { Grad/professional }=10.0\end{array}$ \\
\hline Government trust (interval) & $.000($ Standard Deviation $=.913)$ \\
\hline Farmer trust (interval) & $.000($ Standard Deviation $=.806)$ \\
\hline Age & $45.77($ Standard Deviation $=18.22)$ \\
\hline Ethnicity & $\begin{array}{l}\text { White }=68.1 \\
\text { Other }=31.9\end{array}$ \\
\hline Sex & $\begin{array}{l}\text { Male }=32.4 \\
\text { Female }=67.6\end{array}$ \\
\hline
\end{tabular}

familiarity with and assessment of their products' risks and willingness to consume them (Slovic, 1992). To this end, three questions provide insight. The first asks "How likely is it that these plants (PMPs or PMIPs) might accidentally enter the U.S. food supply?" and by doing so assesses perceived probability of the individual's exposure to the threat. The question "How much have you seen, read, or heard recently regarding the use of biotechnology or genetic modification in the production of food that is sold in grocery stores?" assesses familiarity with this technology. Finally, the question "How likely would you be to choose to eat genetically modified foods?" can be seen as assessing comfort with consuming this new technology (see Table 1).

The next two questions concern knowledge of science, both in terms of specific objective science knowledge and levels of education (Table 2). A common belief of those in the scientific community, as well as in many policy circles, is that public scientific literacy leads to greater support for science and technology (Gaskell, Thompson, \& Allum, 2002; Hoban, 1997; Miller, 1998). However, this has not been supported cross-culturally, with superior scientific literacy leading to greater acceptance in some cases and higher levels of rejection in other situations (Chess, 1998; Gaskell et al., 2002). In other words, interest, and hence, knowledge of science might be driven by proponents of progress in science and technology as well as skepticism concerning its threat to society (Gaskell et al., 2001).

Specific objective science knowledge is measured through the ability of respondents to correctly identify whether each of four statements are true or false. The correct answers are then summed to create a general knowledge scale. Here we use questions from a 2001 National Science Foundation (NSF) survey of American's science and technology knowledge (Miller, Kimmel, ORC Macro, 2001), allowing for comparison of the NSF national study and the regional sample analyzed here. 
Findings suggest the regional sample has slightly higher levels of objective knowledge of science facts than the $2001 \mathrm{NSF}$ study. ${ }^{3}$

Highest level of education attained serves as a proxy measure of overall science knowledge as well as an indicator of familiarity with the societal institution of education, which in turn may inculcate trust in institutions generally. Like specific objective science knowledge, it is generally believed those with higher educations are more likely to accept new technologies. Here we treat education, ranging from not finishing high school to obtaining a graduate or professional degree, as a categorical variable.

Trust in the regulatory system being implemented by the government and the food processing system being employed by farmers are also seen as important in the acceptance of the products of agricultural biotechnology. Essentially, trust is seen as functioning to assure certainty in the future in the absence of direct knowledge (Gaskell et al, 2002; Gaskell et al., 2001; Harrison \& Han, 2005; Savadori et al., 2004; Siegrist, 2000; Siegrist \& Cvetkovich, 2000; Siegrist et al., 2007). As such, institutions serve as buffers against the uncertainty of the outside world. Therefore, trust can be expected to lead to lower levels of worry over new technologies such as genetically modified products, even though such products as PMIPs and PMPs are not being grown in the traditional farming situation but in a highly regulated situation specific to these products (Stewart \& Knight, 2005; Taylor et al., 2004).

To assess trust we asked survey respondents their levels of trust in the institutions responsible for food safety in the United States. The first three questions consider government institutions, which are responsible for regulating the new agricultural biotechnology (U.S. Department of Agriculture [USDA], U.S. Environmental Protection Agency [EPA], and the U.S. Food and Drug Administration [FDA]). The second type of institution is at the farm level and is assessed by asking questions concerning corporate and family farms, which are responsible for the food supply and its safety. We then ran a principle components factor analysis with two factors being extracted, one for government institutional trust and one for trust in farmers. ${ }^{4}$

Finally, we assessed the impact of such demographic variables of age, sex, and ethnicity on support for third-generation agricultural biotechnology products. Age is an interval variable, ranging from 18 to 93 years of age. The numbers concerning sex show that women make up two-thirds of the sample due to both their proportion in the population and their tendency to answer telephones. Finally, ethnicity is dichotomized to reflect the majority white population and the minority populations, made up of African-Americans, Latinos, and American Indians.

\section{Methods}

The current study involved 10- to 15-minute phone interviews with a random sample of consumers in a five-state region representing EPA Region $6 .{ }^{5}$ The study examined Arkansas, Louisiana, Texas, Oklahoma, and New Mexico. Interviews were conducted between May 9 and June 10, 2004 by paid, trained, and supervised interviewers of the Arkansas State University Center for Social Research (ASU-CSR) using computer assisted telephone interviewing (CATI) technology. The response rate was very good, with a total of 680 interviews completed for a response rate of 61 percent and a margin of error of $+/-3.5$ percent. 
To further validate the generalizability of the study's sample, findings are compared with a study carried out the previous year by PEW on a national sample of 1,000 Americans. Specifically, questions concerning awareness of genetically modified goods sold in grocery stores and willingness to eat genetically modified food were asked in this study and compared with findings on the same questions asked in the previous year's survey by PEW. Findings suggest substantial equivalence between the studies concerning awareness, within the 3.5 margin of error for both studies, with the public indicating low levels of contact with information about genetically modified foods being sold in grocery stores. In terms of respondent choice to eat genetically modified foods, while differences do exist with the Region 6 respondents seeing themselves as less likely to do so than PEW respondents, these differences are relatively minor.

\section{Results}

To ensure participants discriminate first-perceived individual benefits and how worried they would be if they ate food coming from PMIP/PMP plants, we first ran a correlation analysis. Benefits of these third-generation plants are only moderately and positively correlated with each other (Spearman's rho $=.334$ ), as are worries (Spearman's rho $=.500$ ), and significant at the .01 level, suggesting a level of validity in separating the third-generation plant types. Correlation of benefits from PMIPs/PMPs with worries over eating PMIPs/PMPs accidentally suggest there is little to no correlation, with PMIP benefits and worries over eating them inadvertently being weak and nonsignificant (Spearman's rho =-.057) and PMP benefits and worries over inadvertent consumption reaching significance at the .05 level, yet having a weak and negative correlation (Spearman's rho $=-.104$ ).

To test the effects of these variables on perceptions of the third generation of agricultural biotechnology's products benefits and how much worry they cause, we ran four ordinary least squares (OLS) regression equations. We assess whether the models are statistically significant by considering the $F$-test and evaluate what percent of the dependent variables of benefits and worries over PMIPs and PMPs variance is explained by the independent variables by considering the adjusted R-square, which controls for the number of variables and cases in the equation. Variable statistics are then assessed. We consider which variables have a significant effect on benefits and worries through $t$-values, we then compare the relative power each has within the respective equations by analyzing the standardized beta coefficient.

Going further, we realize that the use of rank-categorized dependent variables may raise concerns about the presence of heteroskedasticity, rendering the OLS estimations inefficient, and the $t$-tests and $F$-test invalid. To ensure that heteroskedasticity was not an issue, and was not suppressing any of the models, we plotted all variables for each of the models to test for its presence. For parsimony, we do not include each of the plots, but there was significant dispersion of each of the variables across each of the categories of the dependent variable, suggesting normalcy in the variables' distribution.

In addition, we realize there may be risks of multicollinearity, which would also result in inefficient estimates. To test for the presence of multicollinearity we utilized VIF scores to ensure that our regressors were not too highly correlated. In each of 
Table 3. OLS Regression Estimates for Benefits of Plant-Made Industrial Products (PMIPs) and Plant-Made Pharmaceuticals (PMPs)

\begin{tabular}{|c|c|c|c|c|}
\hline \multirow[b]{2}{*}{ Variable } & \multicolumn{2}{|c|}{ PMIPs $(N=489)$} & \multicolumn{2}{|c|}{$\operatorname{PMPs}(N=483)$} \\
\hline & $\begin{array}{c}\text { Standardized } \\
\text { coefficient }\end{array}$ & $t$-value & $\begin{array}{c}\text { Standardized } \\
\text { coefficient }\end{array}$ & $t$-value \\
\hline $\begin{array}{l}\text { How likely is it to accidentally enter the } \\
\text { food supply? }\end{array}$ & .03 & .69 & .08 & 1.81 \\
\hline $\begin{array}{l}\text { Seen/read/heard much about GM food in } \\
\text { grocery stores? }\end{array}$ & .09 & $2.12^{*}$ & .11 & $2.43^{*}$ \\
\hline Would you eat GM food? & .12 & $2.79 * *$ & .06 & 1.27 \\
\hline Science knowledge & -.004 & -.075 & .04 & 1.01 \\
\hline Education & -.084 & -1.75 & -.008 & -.185 \\
\hline Government trust & -.02 & -.58 & -.07 & -1.49 \\
\hline Farmer trust & -.14 & $-3.22 * * *$ & -.151 & $-3.24 * * *$ \\
\hline Age & .06 & 1.40 & .09 & $2.12^{*}$ \\
\hline Ethnicity & .11 & $2.50^{*}$ & -.008 & -.185 \\
\hline \multirow[t]{2}{*}{ Sex } & .02 & .52 & .004 & .091 \\
\hline & Adj. $\mathrm{R}^{2}=.07$ & $\mathrm{~F}=4.995 * * *$ & Adj. $\mathrm{R}^{2}=.04$ & $\mathrm{~F}=3.330^{* * * *}$ \\
\hline
\end{tabular}

${ }^{*} \mathrm{p}<.05$ level of significance; $* * \mathrm{p}<.01$ level of significance; $* * * \mathrm{p}<.001$ level of significance.

the models there was no detection of multicollinearity, with no regressor achieving a higher VIF score than 1.2, well below the accepted range of 5 in standard econometric research.

Further, we use multinomial logistic regression as a confirmatory method of the overall strength of the models (see Appendix B). However, since we are not attempting data reduction for a parsimonious model, we report the OLS estimates here to assess significance, direction, and strength of association for each predictor variable.

The first equation considers what determines perceptions of benefits from PMIPs (see Table 3). The model itself is significant with 7 percent of the dependent variable's variance explained once the number of variables and subjects are adjusted for. Specific knowledge and beliefs concerning the biotech products have a significant and positive effect with those having been exposed to information about GM food in grocery stores having a significant and the third-strongest effect on perceived individual benefits, whereas willingness to eat GM foods is highly significant and has the strongest effect. Trusting farmers, whether family or corporate, is the second most powerful variable and operates in a positive fashion, with more trust in farmers leading to greater perceived benefits. Finally, ethnicity is significant, with whites more likely to see individual benefits than minorities.

Perceived individual benefits from PMPs likewise function as a significant model $(F$-test $<.001)$ with independent variables explaining 4 percent of the variance after adjusting for number of variables and cases (see Table 3). Three variables achieve significance with the factor trust in farmers playing a positive and the strongest role in determining perceived individual benefit. Finally, individual exposure to information about food biotechnology in grocery stores plays a significant and positive role in perceptions of benefits, while age plays a slight significant and positive role in perceptions of benefits.

The regression model concerning how worried respondents would be if they ate food coming from PMIPs is more statistically significant and explains 13 percent of the variance after controlling for number of variables and cases (see Table 4). Five variables play a significant role in determining subject worry, with the most pow- 
Table 4. OLS Regression Estimates for Worry over PMIPs and PMPs

\begin{tabular}{|c|c|c|c|c|}
\hline \multirow[b]{2}{*}{ Variable } & \multicolumn{2}{|c|}{ PMIPs $(N=500)$} & \multicolumn{2}{|c|}{ PMPs $(N=504)$} \\
\hline & $\begin{array}{c}\text { Standardized } \\
\text { coefficient }\end{array}$ & $t$-value & $\begin{array}{c}\text { Standardized } \\
\text { coefficient }\end{array}$ & $t$-value \\
\hline $\begin{array}{l}\text { How likely is it to accidentally enter the } \\
\text { food supply? }\end{array}$ & .22 & $5.32^{* * * *}$ & .11 & $2.67 * *$ \\
\hline $\begin{array}{l}\text { Seen/read/heard much about GM food in } \\
\text { grocery stores? }\end{array}$ & .06 & 1.40 & .05 & 1.14 \\
\hline Would you eat GM food? & -.12 & $-2.93 * *$ & -.07 & -1.69 \\
\hline Science knowledge & -.007 & -.15 & .03 & .78 \\
\hline Education & .11 & $2.42 *$ & .09 & $1.99 *$ \\
\hline Government trust & -.02 & -.58 & .04 & 1.02 \\
\hline Farmer trust & .11 & $2.54^{*}$ & .13 & $2.95 * *$ \\
\hline Age & .11 & $2.71^{* *}$ & .03 & .82 \\
\hline Ethnicity & -.09 & $-2.11 *$ & -.03 & -.74 \\
\hline \multirow[t]{2}{*}{ Sex } & -.04 & -1.12 & -.04 & -1.075 \\
\hline & Adj. $\mathrm{R}^{2}=.13$ & $\mathrm{~F}=8.681^{* * * *}$ & Adj. $\mathrm{R}^{2}=.05$ & $\mathrm{~F}=4.069^{* * *}$ \\
\hline
\end{tabular}

$* \mathrm{p}<.05$ level of significance; $* * \mathrm{p}<.01$ level of significance; $* * * \mathrm{p}<.001$ level of significance.

erful variable being how likely PMIPs are to accidentally enter the food supply, with increases in the perception of adventitious presence leading to enhanced worry. The next most powerful variable is likelihood of eating GM food, which has a significant and negative impact on worry as those more likely to eat GM food exhibit less worry. Age and education, the third and fourth most powerful variables, leads to decreased worry the older and more educated subjects get. Finally, ethnicity is significant, with minorities more likely to worry.

Determinants of how worried respondents would be if they ate food coming from PMPs showed the model to be equally significant to the first model, explaining 5 percent of the variance. Three variables are significant in this model: likelihood of PMPs entering the food supply, trust in farmers, and level of education. The most powerful variable is that of trust in corporate and family farmers, which leads to lower levels of worry as trust increases. The second most powerful variable is perceived likelihood of PMPs entering the food supply as increases in perceived likelihood of exposure leads to increased worry. Finally, increased education leads to decreased worry over eating food containing PMPs.

\section{Discussion}

One of the key aspects of this study is the ability to compare perceptions of agricultural biotechnology's third generation of products and what drives these perceptions. Findings suggest that perceptions of respondents from the five-state region toward the technology cluster of PMIPs and PMPs, although significantly different, are not greatly differentiated. However, on the whole, the respondents to this study see more personal benefit from PMPs than from PMIPs and are worried less about consuming PMPs than PMIPs. When OLS regression equations are run, findings show that while some variables have shared pertinence for determining attitudes toward PMIPs and PMPs, there are also differences. Because of the variance in variables explaining perceptions of benefits and determinants of worry, those communicating to the public should consider taking different approaches to 
conveying information about PMIPs and PMPs. Later, we consider the implications of our findings on perceptions of benefits and the worries individuals might have over eating third-generation genetically modified plants.

\section{Individual Benefits from PMIPs and PMPs}

A variety of variables play a role in explaining why individuals perceive benefits from PMIPs and PMPs to themselves. Respondent's professed exposure to information, whether seen, read, or heard, about GM food in grocery stores leads to greater perceived benefits from both PMIPs and PMPs. This suggests that public communication in the region studied has either tended to be positive or has resonated in a positive manner. Likewise, willingness to eat GM food has a significant and positive effect on perceived benefits from PMIPs (indeed, it is the most powerful variable in the equation), although not for PMPs. What this suggests is that there might be a closer link in the respondents' minds between GM foods and PMIPs than there is between GM food and PMPs.

Other important implications concern institutional trust. For our subjects institutional trust is differentiated, with government and farmers being considered as separate entities. Findings concerning trust suggest the more respondents trust farmers, whether family or corporate, the more they will perceive benefits from both PMIPs and PMPs. This is in spite of it being likely the case that traditional farming systems will not be used to grow third-generation products in the United States due to concerns over these plants entering the food supply and specific regulations prohibiting mixing of plants destined for the food system with PMIPs or PMPs (Stewart \& Knight, 2005).

Where the equations concerning personal benefits from third-generation products diverge is that willingness to consumer GM food, increased education, and being white (as compared to minority-black, Latino, American Indian) leads to increases in perceived benefits from PMIPs but not PMPs.

\section{Individual Worries over PMIPs and PMPs}

Respondent worry over potentially eating third-generation products is likewise driven both by variables in common and specific to PMIPs and PMPs. A powerful variable in both equations is the perceived likelihood of either PMIPs or PMPs entering into the food supply. While the finding that greater perceived likelihood of exposure by these plants accidentally entering the U.S. food supply leads to greater worry can be expected, the divergence of the relative power of this variable in the different equations is somewhat unexpected. Exposure is almost twice as powerful in driving worries over eating PMIPs as compared to PMPs.

Likewise education is an important variable in both equations, with greater education leading to less worry. This follows the literature and may suggest that the more time an individual spends in societal institutions, the more trust there is in societal institutions generally. Interestingly, objective science knowledge does not play a role in any of the equations, suggesting basic science knowledge is not important for accepting or rejecting these new technologies. 
Where the equations diverge is that, where PMIPs are concerned, the greater likelihood of eating GM food leads to less worry over these plants, suggesting greater faith in GM goods. Increased age also leads to less worry over thirdgeneration GM products and their consumption, which may reflect societal changes as younger individuals tend to be more concerned with environmental issues.

Trust plays an important role in how worried individuals are about eating food with PMPs in it. The more respondents trust family and corporate farmers, the less worried they are about eating food with PMPs in it. Institutional trust, namely in farmers, thus is key for understanding perceptions of risk from eating food with pharmaceutical drugs, even though these farmers are likely not responsible for growing plants containing pharmaceutical drugs. That trust in farmers plays a role for PMPs but not PMIPs is unexpected and suggests that, at least in this circumstance, family and corporate farmers might be seen as implicated in growing these drugs, and as such, have a stake in the regulation and perceptions of this technology. Although public trust in farmers has not visibly diminished as a result of the regulated Bt corn and experimental PMP corn entering the food supply, concern has been piqued in food producers and the interested public (Stewart \& McLean, 2005a) and likely would be aroused in the public if there was a large-scale accidental release of PMIPs or PMPs into the food supply.

\section{Conclusions}

Public response toward the third generation of agricultural biotechnology cannot be predicted with a high degree of confidence, especially considering the current low levels of public awareness of GM plants in the food supply. However, growing concern over the accidental release of GM plants into the food supply suggest this is an area of high salience for decision makers in government and the food industry. Perhaps the most sobering finding of this study is the lack of a relationship between trust in the federal institutions responsible for safeguarding our food supply, specifically, the USDA, the EPA, and the FDA and perceptions of benefits from PMIPs and PMPs or the worry (or lack thereof) over their entering the food supply and being consumed by respondents. Whether this is because of a statistical anomaly, regional attitudes toward these government agencies, or is part of a national trend, governmental institutions are key for obtaining and maintaining public trust in how new technologies such as PMIPs and PMPs are regulated. And as institutional trust has been shown in multiple studies as a proxy for knowledge, the importance of maintaining and enhancing institutional trust is highly significant in modern society, especially when dealing with a topic as vital and personal as the food people eat.

Furthermore, that trust in farmers, whether corporate or family, is a major factor driving perception of benefits of both PMPs and PMIPs and worries over PMPs suggests that, in spite of their lack of direct involvement in the development and production of PMPs and PMIPs, farmers have a specific interest in how these crops are developed and managed. This is especially important as farmers stand to lose much more than what they stand to gain, both financially and in terms of public trust. While personal experience of respondents with biotechnology plays a role both in perceptions of benefits and worries over eating food accidentally commingled with these third-generation products of agricultural biotechnology, under- 
scoring the rational self-interested nature of the public in the face of new technologies (Page \& Shapiro, 1992), ultimately it is public trust in societal institutions and their ability to respond to public concerns that likely will determine the future of these products.

\section{Acknowledgments}

The authors would like to thank the Arkansas Bioscience Institute (ABI) of Arkansas State University for funding this research project. The authors would also like to thank the anonymous reviewers for their detailed and insightful comments, which greatly strengthened this paper. If there are any weaknesses in the paper, the responsibility lies solely with the authors.

\section{Notes}

1. The findings of Losey, Rayor, and Carter (1999) were corroborated to a certain extent by studies sponsored by the USDA and an industry-funded research group. Here, it was shown that some forms of GM corn plants with pesticidal qualities increased mortality rates of Monarch butterflies, while other forms of these corn plants did not have the same impact on mortality (NRC, 2002, pp. 34-5).

2. While management strategies to maintain the effectiveness of plants genetically modified to express Bt., a pesticidal protein, have been successful in many parts of the country (most notably with Bt cotton in Arizona), refuge management, in which populations of genetically susceptible insects are allowed to reproduce in order to prevent adaptation through reproductive selection, has not been completely successful. Specifically, reports suggest resistance developing in the Midsouth region, specifically in Arkansas and Mississippi, likely due to the refuge management strategy not being correctly implemented (Tabashnik et al., 2008).

3. The first statement " $[\mathrm{t}]$ he oxygen we breathe comes from plants" (True; NSF $=87 \%$; ABI $=89.7 \%$ ). The second statement "[i]t is the father's gene which decides whether a baby is a boy or a girl" (True; $\mathrm{NSF}=65 \%$; $\mathrm{ABI}=68.5 \%$ ). The third statement "[a]ntibiotics kill viruses as well as bacteria" (False; NSF 51\%; ABI $=54.6 \%)$. And finally, the fourth statement was "[r]adioactive milk can be made safe by boiling it" (False; NSF $=65 \%$; ABI $=70.3 \%$ ).

4. To assess trust, we ran a principle components factor analysis with a varimax rotation on five trust variables. These variables assessed trust in federal regulatory agencies and farmers on a five-point scale and loaded on two variables. The first factor, trust in government institutions, has an eigenvalue of 2.838 and explains 56.75 percent of the variance with USDA (.839), EPA (.882) and FDA (.890) loading strongly on the variable after rotation. The second factor, trust in farmers, has an eigenvalue of 1.049 and explains 20.982 percent of the variance, with corporate farmers loading at .752 and family farmers loading at .901 .

5. EPA Region 5 was selected for a number of reasons including its diverse agrarian features (e.g., corn, cotton, rice, wheat, cattle), regional cultural differences in attitudes (e.g., Arkansas is a Southern state, whereas New Mexico is identified by some as a Southwestern and as a Western state by others), and the presence of both rural and urban public opinion (e.g., the sample contains residents from towns smaller than 100 residents and also residents from such urban centers as New Orleans and Dallas). All surveys included only adults and were stratified by state and race to ensure exact representation on those variables. Furthermore, respondent statistics indicate that the sample proved to accurately stratify by state, race, gender, education level, and age according to comparison with the United States Census. Samples, drawn by Survey Sampling Incorporated of Fairfield, CT, used a random digit dialing procedure to which the CSR applied a screen for adults and further guaranteed randomness through a date of birthday screen as well. Response rate number 3 in Standard Definitions: Final Disposition of Case Codes and Outcome Rates for RDD Telephone Surveys and In-Person Household Surveys, by the American Association for Public Opinion Research, was computed. This is the completion rate among those phone numbers where eligibility is known plus an assumption that, among the unknown numbers, eligibility is the same among the known numbers. The response rate was 61 percent. Interviewers for all surveys were a mix of paid students, workers, and employees solicited and paid 
by the CSR. The interviews were conducted from a central phone bank with constant supervision by either a professor or graduate student in public administration.

\section{About the Authors}

Patrick A. Stewart is Assistant Professor in the Department of Political Science at the University of Arkansas. He has published extensively in agricultural biotechnology policy over the past 15 years. He will be moving from Arkansas State University, where he was director of the Masters of Public Administration program and codirector of the Center for Social Research, to the University of Arkansas in the Fall of 2008.

William P. McLean is Assistant Professor in the Department of Political Science at Arkansas State University. He teaches in the Masters of Public Administration Program and is codirector of the Center for Social Research. He has published widely in he areas of service delivery, public opinion, and regulatory policy.

\section{References}

Brader, T. (2006). Campaigning for hearts and minds: How emotional appeals in political ads work. Chicago: University of Chicago Press.

Chess, C. (1998). Fearing fear: Communication about agricultural biotechnology. Agbioforum, 1, 17-21.

Ekman, P., \& Davidson, R. J. (Eds.). (1994). The nature of emotion: Fundamental questions. New York: Oxford University Press.

Fischhoff, B., \& Fischhoff, I. (2001). Public's opinions about biotechnologies. AgBioForum, 4, 155-162.

Gaskell, G., Allum, N., Wagner, N. T. H., Jelsoe E., Kohring, M., \& Bauer, M. W. (2001). The structure of public perceptions. In G. Gaskell \& M. W. Bauer, (Eds.), The public eye: Representations of biotechnology in Europe. Biotechnology 1996-2000: The years of controversy (pp. 53-79). London: National Museum of Science and Industry.

Gaskell, G., Thompson, P., \& Allum, N. (2002). Worlds apart? Public opinion in Europe and the USA. In M. W. Bauer \& G. Gaskell (Eds.), Biotechnology-The making of a global controversy (pp. 351-375). Cambridge, UK: Cambridge University Press.

Hallman, W. L., Hebden, W. C., Cuite, C. L., Aquino, H. L., \& Lang, J. T. (2004). Americans and genetically modified food: Knowledge, opinion and interest in 2004 (Publication number RR-1104-007). New Brunswick, NJ: Food Policy Institute, Cook College, Rutgers-the State University of New Jersey.

Harrison, R. W., \& Han, J.-H. (2005). The effects of urban consumer preferences on attitudes for labeling of genetically modified foods. Journal of Food Distribution Research, 36, 29-38.

Hoban, T. J. (1997). Consumer acceptance of biotechnology: An international perspective. Nature Biotechnology, $15,232-234$

Lerner, J. S., Gonzalez, R. M., Small, D. A., \& Fischhoff, B. (2003). Effects of fear and anger on perceived risks of terrorism. Psychological Science, 14, 144-150.

Lewis, M., \& Haviland-Jones, J. M. (2004). Handbook of emotions (2nd ed.). New York: Guilford Press.

Losey, J. E., Rayor, L. S., \& Carter, M. E. (1999). Transgenic pollen harms Monarch butterflies. Nature, $399,214$.

Marcus, G. E., Neuman, W. R., \& MacKuen, M. (2002). Affective intelligence and political judgment. Chicago: University of Chicago Press.

Midden, C., Boy, D., Einsiedel, E., Fjaestad, B., Liakopoulos, M., Miller, J. D., et al. (2002). The structure of public perceptions. In M. W. Bauer \& G. Gaskell (Eds.), Biotechnology-The making of a global controversy (pp. 203-223). Cambridge, UK: Cambridge University Press.

Miller, J. D. (1998). The measurement of civic scientific literacy. Public Understanding of Science, 7, 203-223.

Miller, J. D., Kimmel, L., \& ORC Macro. (2001). National Science Foundation surveys of public attitudes toward and understanding of science and technology, 1979-2001. Storrs, CT: Roper Center for Public Opinion Research.

National Research Council (NRC). (2002). Environmental effects of transgenic plants: The scope and adequacy of regulation. Washington, DC: National Academy Press.

Office of Inspector General (USDA-OIG). (2005). Audit report: Animal and plant health inspection service controls over issuance of genetically engineered organism release permits. Audit 50601-8-Te December.

Page, B. I., \& Shapiro, R. Y. (1992). The rational public: Fifty years of trends in American's policy preferences. Chicago: University of Chicago Press.

Panksepp, J. (1998). Affective neuroscience: The foundations of human and animal emotions. New York: Oxford University Press. 
Peters, E. M., Burraston, B., \& Mertz, C. K. (2004). An emotion-based model of risk perception and stigma susceptibility: Cognitive appraisals of emotion, affective reactivity, worldviews, and risk perceptions in the generation of technological stigma. Risk Analysis, 24, 1349-1367.

PEW Initiative on Food and Biotechnology (PEW). (2004). Public sentiment about genetically modified food. Mellman Group, Inc./Public Opinion Strategies for the Pew Initiative. Washington, DC: Pew Initiative on Food and Biotechnology. Retrieved May 27, 2005, http://pewagbiotech.org/research/2004update/overview.pdf

Poortinga, W., \& Pidgeon, N. F. (2006). Exploring the structure of attitudes toward genetically modified food. Risk Analysis, 6, 1707-1719.

Rosenwald, M. S. (2005). Syngenta says it sold wrong biotech corn. Washington Post. March 23, p. E01. Retrieved March 28, 2005, from http://www.washingtonpost.com/ac/wp-dyn/A58449-2005Mar22/

Savadori, L., Savio, S., Nicotra, E., Rumiati, R., Finucane, M., \& Slovic, P. (2004). Expert and public perceptions of risk from biotechnology. Risk Analysis, 24, 1289-1299.

Schubert, J. N., Stewart, P. A., \& Curran, M. A. (2002). A defining presidential moment: 9/11 and the rally effect. Political Psychology, 23, 559-583.

Siegrist, M. (2000). The influence of trust and perceptions of risks and benefits on the acceptance of gene technology. Risk Analysis, 20, 195-205.

Siegrist, M., Cousin, M.-E, Kastenholz, H., \& Wiek, A. (2007). Public acceptance of nanotechnology foods and food packaging: The influence of affect and trust. Appetite, 49, 459-466.

Siegrist, M., \& Cvetkovich, G. (2000). Perception of hazards: The role of social trust and knowledge. Risk Analysis, 20, 713-719.

Slovic, P. (1992). Perception of risk: Reflections on the psychometric paradigm. In S. Krimsky \& D. Golding (Eds.), Social theories of risk (pp. 117-152). Westport, CT: Praeger Press.

Stewart, P. A. (in press). Policy and regulatory challenges for plant made pharmaceuticals in the United States. In E. Einsiedel (Ed.), Hindsight and foresight on emerging technologies. Pullman, WA: University of British Columbia/University of Washington Presses.

Stewart, P. A., \& Knight, A. J. (2005). Trends affecting the next generation of U.S. agricultural biotechnology: Politics, policy and plant-made pharmaceuticals. Technology Forecasting E Social Change, 72, 521-534.

Stewart, P. A., \& McLean, W. P. (2005a). Fear and hope over the third generation of agricultural biotechnology. AgBioForum, 7, 133-141. Retrieved May 27, 2005, from http://www.agbioforum.org/v7n3/v7n3a05stewart.htm

Stewart, P. A., \& McLean, W. P. (2005b). Public opinion toward the first, second and third generations of plant biotechnology. In Vitro Cellular and Developmental Biology-Plant, 41, 718-724.

Stewart, P. A., \& Sorensen, A. A. (2000). Federal uncertainty or inconsistency? Releasing the new agriculturalenvironmental biotechnology into the fields. Politics and the Life Sciences, 19, 77-88.

Tabashnik, B. E., Gassmann, A. J., Crowder, D. W., \& Carriere, Y. (2008). Insect resistance to Bt crops: Evidence versus theory. Nature Biotechnology, 26, 199-202.

Taylor, M. R., Tick, J. S., \& Sherman, D. M. (2004). Tending the fields: State and federal roles in the oversight of genetically modified crops. Washington, DC: Pew Initiative on Food and Biotechnology.

Townsend, E., \& Campbell, S. (2004). Psychological determinants of willingness to taste and purchase genetically modified food. Risk Analysis, 24, 1385-1393.

Townsend, E., Clark, D. D., \& Travis, B. (2004). Effects of context and feelings on perceptions of genetically modified food. Risk Analysis, 24, 1369-1384.

U.S. Department of Agriculture (USDA). (2007). Syngenta Seeds, Inc.: Availability of determination of nonregulated status for corn genetically engineered for insect resistance. Federal Register, 72, 12736-13737.

Wilson, C., Evans, G., Leppard, P., \& Syrette, J. (2004). Reactions to genetically modified food crops and how perception of risks and benefits influences consumers' information gathering. Risk Analysis, 24, 1311-1321.

\section{APPENDIX A}

\section{Survey Questions}

\section{Plant-Made Industrial Products Series}

I would next like to ask you a few questions about plants genetically modified to produce industrial products. These are plants that are modified to produce compounds used in manufacturing products such as paper, plastics and laundry products. (Questions $=$ Benefit, Release, Worried) 


\section{Plant-Made Pharmaceuticals Series}

I would next like to ask you a few questions about plants genetically modified to produce pharmaceutical drugs. These are plants that are modified to produce compounds used in manufacturing vaccines for diarrhea, antibodies to fight cancer, and drugs to treat such illnesses as cystic fibrosis. (Questions = Benefit, Release, Worried)

\section{Question Wording}

Benefit-How much benefit do you believe you would personally get from this type of plant? (4 A great deal, 3 some, 2 a little, 1 none at all, 8 DK, 9 Refused).

Release-How likely is it that these types of plants might accidentally enter the U.S. food supply? (5 Very likely, 4 Somewhat likely, 3 Neither likely or unlikely, 2 Somewhat unlikely, 1 Very unlikely, 8 DK, 9 Refused).

Worried-How worried would you be if you ate food coming from this type of plant? (5 Very worried, 4 Quite a bit worried, 3 Moderately worried, 2 Slightly worried, 1 Not at all worried, 8 DK, 9 Refused).

\section{APPENDIX B}

\section{Multinomial Logistic Regression Models}

To test what drives perceptions of the third generation of agricultural biotechnology product benefits and how much worry they cause, we ran four multinomial logistic regression equations treating all variables, with the exception of trust in farmers and government agencies, as categorical. Model chi-square tests determine the overall significance of each of our four models by using the reduced model as the baseline model with the constant only, with the likelihood ratio test allowing us to assess the significance of the overall model. Findings for all four models show them as highly significant at the .01 level of significance (PMIP benefits $\chi^{2}=165.13$, PMP benefits $\chi^{2}=125.28$, PMIP worries $\chi^{2}=217.25$, PMP worries $\chi^{2}=156.89$ ). We likewise report the Nagelkerke $\mathrm{R}^{2}$, a modification of the Cox and Snell $\mathrm{R}^{2}$ that ranges from 0 to 1 . Nagelkerke $\mathrm{R}^{2}$ is not a goodness-of-fit test but rather an attempt to measure strength of association and is only an approximation to OLS $\mathrm{R}^{2}$, not an actual percent of variance explained. Here, our findings suggest good strength as a measure of association for all four models (PMIP benefits Nagelkerke $\mathrm{R}^{2}=.311$, PMP benefits Nagelkerke $\mathrm{R}^{2}=.250$, PMIP worries Nagelkerke $\mathrm{R}^{2}=.366$, PMP Nagelkerke $\mathrm{R}^{2}$ worries $=.280$ ). In other words, the findings of our multinomial logistic regressions mirror those of the OLS regressions.

Analysis of the coefficients themselves support the findings of the OLS regression, with the models' findings reflecting those discussed in text in terms of significance and direction of the relationships. Therefore, given the robustness of OLS regression generally, that the four models did not deviate greatly from the best linear unbiased 
estimate assumptions (BLUE), as assessed through the diagnostics discussed in text, and the straightforward nature of this approach, which allows for the conveying of the significance, direction, and power of relationships between independent and dependent variables, we rely on OLS regression as the chief method of analysis. 